\title{
ANALYSIS OF TOTAL FLAVONOID LEVELS OF ETHANOL EXTRACT (Cinnamon (Cinnamomum burmanii Blume) LEAVES WITH UV-VIS SPECTROPHOTOMETRY METHOD
}

\author{
Darmayuda, I P. P. ${ }^{1)}$; Suardana, I G. ${ }^{2)}$; Bawa Putra, A. A. ${ }^{3)}$ \\ ${ }^{1)}$ Laboratorium Kimia Anorganik, PS Kimia FMIPA Universitas Udayana, Bali; tudahe69@gmail.com \\ ${ }^{2)}$ Laboratorium Kimia Lingkungan, PS Kimia FMIPA Universitas Udayana, Bali; gedesuardana240966@gmail.com \\ ${ }^{3)}$ Laboratorium Kimia Anorganik, PS Kimia FMIPA Universitas Udayana, Bali; bawa_putra@unud.ac.id
}

\begin{abstract}
Cinnamon plants (Cinnamomum burmani Blume), including plants that have medicinal properties for diabetes mellitus because they contain flavonoid compounds. This study aimed to determine the total flavonoids content of the ethanol extract of cinnamon leaf ethanol extract using UV-Vis spectrophotometry method. The ethanol extract of Cinnamon leaf was obtained by maceration using ethanol as a solvent.The qualitative analysis used $\mathrm{FeCl}_{3}$ by forming yellowish green complex. The determination of total flavonoids content is conducted basedon $\mathrm{AlCl}_{3}$ method with total flavonoidse xpressed in QE (Quercetin equivalent) at the maximum wavelength of $435 \mathrm{~nm}$. The result showed that the average content of flavonoid total is $19.544 \mathrm{mg} Q E / g$ extract.
\end{abstract}

Keywords: flavonoid total; cinnamon plants (Cinnamomum burmanii Blume); UV-Vis spectrometry.

\begin{abstract}
ABSTRAK
Tanaman kayu manis (Cinnamomum burmani Blume), termasuk tanaman yang berkhasiat obat diabetes melitus karena mengandung senyawa flavonoid. Penelitian ini bertujuan untuk mengetahui kandungan flavonoid total ekstrak etanol daun kayu manis dengan metode spektrofotometri UV-Vis. Ekstrak etanol daun kayu manis diperoleh dengan cara maserasi menggunakann pelarut etanol. Analisis kualitatif menggunakan reagen $\mathrm{FeCl}_{3}$ membentuk kompleks hijau kekuningan. Penentuan kadar flavonoid total dilakukan berdasarkan metode $\mathrm{AlCl}_{3}$ dengan flavonoid total dinyatakan dalam QE (Quercetin equivalent) pada panjang gelombang maksimum $435 \mathrm{~nm}$. Hasil penelitian menunjukkan bahwa rata-rata kandungan flavonoid total adalah 19,554 mgQE/g ekstrak.
\end{abstract}

Kata kunci: flavonoid total; kayu manis (Cinnamomum burmanii Blume); Spektrometri UV-Vis

\section{PENDAHULUAN}

Indonesia merupakan negara yang memiliki kekayaan alam dengan berbagai obat tradisional. Kebutuhan masyarakat obat tradisional semakin banyak diminati karena harganya terjangkau, mudah diracik, bahan nabatinya mudah diperoleh. Salah satu tumbuhan yang menarik untuk diteliti adalah daun kayu manis dari family Cinnamomum burmannii Blume yang merupakan tanaman yang dapat berkhasiat sebagai obat (Ferry, 2013). Penggunaan kayu manis di masyarakat dengan cara direbus dengan air panas. Cara perebusan bahan herbal juga disebut ekstraksi (Saifudin, 2002). Metode ekstraksi dilakukan dengan merebus sampel yaitu dekoksi dan infundasi. Infundasi merupakan metode ekstraksi denganpelarut air. Waktu proses infundasi temperatur pelarut air mencapai suhu $90^{\circ} \mathrm{C}$ selama 15 menit. Rasio berat bahan dan air adalah 1:10. Proses ekstraksi membutuhkan waktu lebih lama ( $\geq 30$ menit) dan suhu pelarut 
sama dengan titik didih air (Anggriawan et al., 2015). Tanaman kayu manis berpotensi sebagai tumbuhan obat karena memiliki kandungan metabolit sekunder yaitu senyawa flavonoid (Arifi dan Ibrahim, 2018).

Flavonoid adalah salah satu senyawa golongan fenol alam terdapat dalam tumbuhan hijau. Menurut (Emilda, 2018), golongan senyawa polifenol memiliki sifat sebagai penghambat enzim hidrolisis, penangkap radikal bebas, meningkatkan aktivitas enzim antioksidan, dan bekerja sebagai anti inflamasi.Pengujian kandungan flavonoid total dari ekstrak etanol daun kayu manis sehingga potensi daun kayu manis sebagai bahan baku obat dilakukan dalam penelitian ini guna pencegahan maupun pengobatan berbagai penyakit dapat lebih dikembangkan dengan maksimal

\section{METODE PENELITIAN \\ Bahan dan Alat Penelitian \\ Bahan penelitian}

Daun kayu manis, etanol 96\%, etanol p.a., $\mathrm{FeCl}_{3}, \mathrm{AlCl}_{3}$, kalium asetat, kuersertin, dan akuades.

\section{Alat yang digunakan}

Seperangkat alat gelas, rotary evaporator, spektrofotometer UV-Vis.

\section{Tempat Penelitian}

Penelitian ini dilakukan di Laboratorium Kimia Anorganik, Laboratorium Kimia Fisik, dan Laboratorium Kimia Organik Program
Studi Kimia FMIPA Universitas Udayana, dan Laboratorium Penelitian Terpadu FMIPA Universitas Udayana.

\section{Prosedur Kerja}

Tahap Pengumpulan dan Penyiapan Sampel

Sampel berupa daun kayu manis (Cinnamomum burmanii Blume), dipetik secara acak dalam kondisi segar sehingga diperoleh umur daun dari yang termuda sampai yang tertua. Tempat pengambilan sampel diperoleh di Desa Belok Kecamatan Petang Kabupaten Badung. Sampel dipotong-potong, dikeringkan dengan bantuan sinar matahari, digiling menjadi serbuk lalu diekstraksi.

\section{Ekstraksi dengan Maserasi Daun Kayu Manis}

Serbuk daun kayu manis dimaserasi menggunakan etanol 96\% selama 24 jam pada suhu kamar. Ekstrak etanol daun kayu manis diperoleh dengan cara penyaringan menggunakan kertas saring. Ekstrak etanol yang diperoleh diuapkan pelarutnya menggunakan rotary evaporator menghasilkan ekstrak etanol kental (Trinovita et al., 2019).

Analisis Kualitatif Kandungan Flavonoid Pada Ekstrak Etanol Daun Kayu Manis

Sebanyak 1 mg ekstrak etanol daun kayu manis ditambahkan 2 tetes $\mathrm{FeCl}_{3}$. Terbentuknya warna hijau atau hijau kekuningan menunjukkan adanya senyawa flavonoid dalam sampel.
Analisis Kuantitatif Kandungan Flavonid Pada Ekstrak Etanol Daun Kayu Manis 
Analisis kandungan falavonoid pada ekstrak etanol daun kayu manis dikerjakan dengan tahap-tahapannya sebagai berikut :

\section{Penentuan Panjang gelombang maksimum \\ Penentuan Panjang gelombang} maksimum kuersertin dilakukan dengan running larutan kuersertin pada range panjang gelombang $400-450 \mathrm{~nm}$, sampel ekstrak etanol daun kayu manis diukur serapannya.

\section{Pembuatan kurva baku kuersetin}

Pembuatan kurva baku kuersetin dilakukan dengan metode yang sudah dikerjakan oleh Trinovita et al. (2019). Ditimbang sebanyak $25 \mathrm{mg}$ baku standar kuersetin dan dilarutkan dalam $25 \mathrm{~mL}$ etanol untuk dijadikan larutan stok. Larutan stok dipipet $1 \mathrm{~mL}$ dan volumenya dibuat hingga $10 \mathrm{~mL}$ dengan etanol sehingga konsentrasi menjadi 100 ppm. Dari larutan standar kuesertin 100 ppm, kemudian dibuat beberapa larutan standar kuesertin yaitu 0 ppm (blanko), 4 ppm,8 ppm, 16 ppm, dan 32 ppm. Larutan standar kuersetin masing-masing dipipet $1 \mathrm{~mL}$, lalu ditambahkan $1 \mathrm{~mL} \mathrm{AlCl}_{3} 2 \%$ dan 1 mL Kalium asetat 120 M kemudian selama 1 jam pada suhu kamar diinkubasi. Absorbansi ditentukan menggunakan metode spektrofotometri UV-Vis pada panjang gelombang maksimum sehingga diperoleh kurva baku

\section{Penetapan kadar flavonoid total ekstrak etanol daun kayu manis}

Kadar flavonoid ditetapkan dengan metode yang dikerjakan oleh Trinovita et al. (2019). Ditimbang sebanyak $100 \mathrm{mg}$ ekstrak etanol daun kayu manis dan dilarutkan dalam $100 \mathrm{~mL}$ etanol sehingga diperoleh konsentrasi 1000 ppm. Dari larutan tersebut dipipet $1 \mathrm{~mL}$, kemudian ditambahkan $1 \mathrm{~mL} \mathrm{AlCl}_{3} 2 \%$ dan $1 \mathrm{~mL}$ Kalium asetat $120 \mathrm{mM}$ selanjutnya diinkubasi selama 1 jam pada suhu kamar. Absorbansi ditentukan menggunakan metode spektrofotometri UV-Vis pada panjang gelombang maksimum. Sampel dibuat dalam 3 ulangan untuk setiap analisis dan diperoleh nilai rata-rata absorban.

\section{HASIL DAN PEMBAHASAN}

Sampel daun kayu manis dikeringkan pada suhu kamar untuk mengurangi kadar air yang terdapat pada sampel, sehingga dapat mencegah pembusukan oleh bakteri, selanjutnya diblender sampai terbentuk bubuk dan diayak sehingga ukurannya homogen. Kadar air pada bubuk daun kayu manis dianalisis dengan metode berat kering hasil pengovenan pada suhu 105 oC. Hasil kadar air bubuk daun kayu manis adalah $12,99 \%$.

Senyawa kimia yang terkandung dalam sampel dilakukan dengan proses ekstraksi. Prinsip ekstraksi didasarkan pada perpindahan masa komponen zat yang terlarut kedalam pelarut sehingga terjadi perpindahan pada lapisan antar muka dan berdifusi masuk kedalam 
pelarut (Saifudin, 2002). Pelarut yang digunakan pada penelitian ini adalah etanol 96\% sebagai pelarut polar.

Metode ekstraksi yang digunakan pada penelitian ini adalah maserasi, karena metode ini lebih sederhana, mudah, dan tanpa pemanasan. Proses maserasi dilakukan 3 replikasi dengan etanol 96\% $200 \mathrm{~mL}$ selama 24 jam. Proses ekstraksi dilakukan 3 kali dengan menambahkan pelarut etanol.

Ekstrak yang diperoleh dipekatkan dengan rotary evaporator sampai diperoleh ekstrak kental yang berwarna hijau kekuning-kuningan. Kemudian dilakukan perhitungan rendamen, dan diperoleh rata-rata persen rendamen yaitu 10,48\%. Kadar metabolit sekunder yang terbawa oleh pelarut ditentukan dengan rendamen (Suharyanto dan Hayati, 2021).

\section{Analisis Kualitatif}

Komponen kimia pada tumbuhan dengan menggunakan reagen besi (III) klorida $\left(\mathrm{FeCl}_{3}\right)$ dilakukan dengan analisis kualitatif. Diamati perubahan warna yang terbentuk yaitu terbentuknya warna merah kehijauan (Saifudin 2002). Hasil identifikasi menunjukkan ekstrak etanol daun kayu manis positif mengandung flavonoid

\section{Analisis Kuantitatif}

Analisis kuantitatif senyawa flavonoid total dengan menggunakan spektrofotometri UV-Vis dilakukan untuk mengetahui seberapa besar kadar flavonoid total yang terkandung pada ekstrak etanol daun kayu manis. Analisis flavonoid dilakukan dengan menggunakan Spektrofotometri UV-Vis karena flavonoid mengandung system aromatic yang terkonjugasi sehingga menunjukkan pita serapan kuat pada daerah spectrum sinar ultraviolet dan spectrum sinar tampak (Saifudin, 2002).

\section{Kurva baku larutan standar kuesertin}

Persamaan garis linier dari larutan standar kuesertin dicari dengan cara membuat sederetan larutan standar kuesertin selanjutnya diukur absorbansinya. Diplot antara konsentrasi dengan nilai absorbansi sehingga diperoleh garis linier dengan persamaan yaikni $\mathrm{y}=$ 0,0249. $\mathrm{x}+0,0021$ dan $\mathrm{R}^{2}=0,9994$ sebagaimana ditunjukkan pada Tabel 1 dan Grafik 1.

Hasil running menunjukkan panjang gelombang maksimum standar kuersetin berada pada panjang gelombang $435 \mathrm{~nm}$.

Tabel 1. Absorbansi Larutan Baku Kuesertin

\begin{tabular}{|c|c|c|c|}
\hline $\begin{array}{c}\text { Konsentr } \\
\text { asi } \\
\text { (ppm) }\end{array}$ & Ulangan & Absorbansi & $\begin{array}{c}\text { Rerata } \\
\text { Absorbansi }\end{array}$ \\
\hline \multirow[t]{3}{*}{0} & 1 & 0,000 & 0,000 \\
\hline & 2 & 0,000 & \\
\hline & 3 & 0,000 & \\
\hline \multirow[t]{3}{*}{4} & 1 & 0,092 & 0,094 \\
\hline & 2 & 0,095 & \\
\hline & 3 & 0,094 & \\
\hline \multirow[t]{3}{*}{8} & 1 & 0,205 & 0,207 \\
\hline & 2 & 0,206 & \\
\hline & 3 & 0,209 & \\
\hline \multirow[t]{3}{*}{16} & 1 & 0,411 & 0,411 \\
\hline & 2 & 0,409 & \\
\hline & 3 & 0,413 & \\
\hline \multirow[t]{3}{*}{32} & 1 & 0,795 & 0,795 \\
\hline & 2 & 0,796 & \\
\hline & 3 & 0,795 & \\
\hline
\end{tabular}




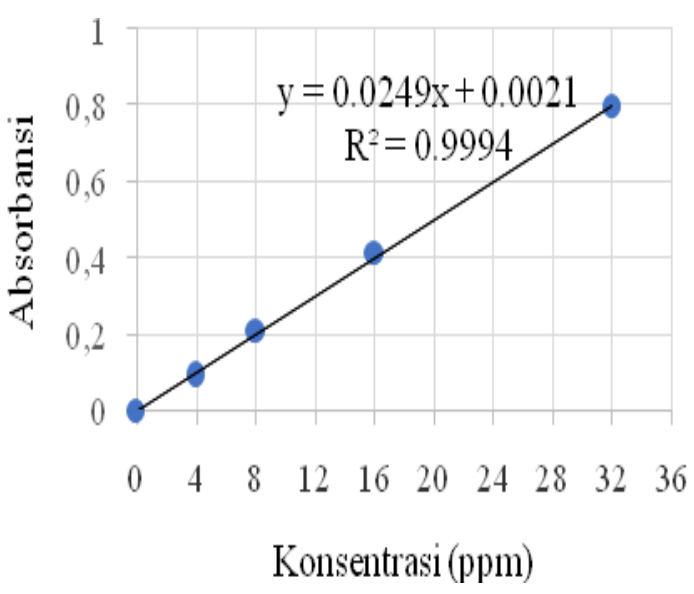

Grafik 1. Kurva Baku Laruta Standar Kuesertin

\section{Kadar flavonoid total pada ekstrak etanol daun kayu manis}

Penentuan kadar flavonoid total yang terkandung pada ekstrak etanol daun kayu manis diukur menggunakan spektrofotometer UV-Vis. Data yang dipeoleh adalah berupa absorbansi dari serapan ektrak etanol daun kayu manis yang selanjutnya diplot ke dalam kurva baku larutan standar kuesertin. Penentuan kadar flavonoid total ekstrak daun kayu manis (Tabel 2).

Tabel 2. Data Pengukuran Kadar Flavonoid Total Esktrak Daun Kayu Manis

\begin{tabular}{|c|c|c|c|c|c|c|}
\hline \multirow[t]{2}{*}{ Ulangan } & \multirow{2}{*}{$\begin{array}{l}\text { Berat Sampel } \\
(\mathrm{mg} / 100 \mathrm{~mL})\end{array}$} & \multirow[t]{2}{*}{ A } & \multicolumn{3}{|c|}{$\mathrm{C}$} & \multirow{2}{*}{$\begin{array}{c}\text { Kadar } \\
\text { (mg QE/g } \\
\text { Sampel) }\end{array}$} \\
\hline & & & $(\mathrm{mg} / \mathrm{L})$ & $(\mathrm{mg} / 100 \mathrm{~mL})$ & $\begin{array}{c}\text { (mg/100 mg } \\
\text { Sampel) }\end{array}$ & \\
\hline 1 & 100 & 0.489 & 19.5542 & 1.9554 & 1.9554 & 19.554 \\
\hline 2 & 100 & 0.492 & 19.6747 & 1.9675 & 1.9675 & 19.675 \\
\hline 3 & 100 & 0.486 & 19.4337 & 1.9434 & 1.9434 & 19.434 \\
\hline & Rerata & & & & & 19.554 \\
\hline
\end{tabular}

Kadar flavonoid total pada ekstrak daun kayu manis (berdasarkan tabel 2) digunakan kuersetin sebagai larutan standar karena kuersetin merupakan gugus ketopada C-4 dan memiliki gugus hidroksil pada atom $\mathrm{C}-3$ atau $\mathrm{C}-5$ yang bertetangga dari flavon dan flavonol (Supriningrum, et al., 2017). Panjang gelombang maksimum standar kuarsetin berada pada panjang gelombang $435 \mathrm{~nm}$ dan panjang gelombang maksimum tersebut yang digunakan untuk mengukur serapan ekstrak etanol daun kayu manis.
Larutan ekstrak etanol daun kayu manis ditambahkan $\mathrm{AlCl}_{3}$ agar terbentuk kompleks, sehingga terjadi pergeseran panjang gelombang kearah visible (tampak) yang ditandai dengan larutan menghasilkan warna yang lebih kuning. Penambahan kalium asetat yang bertujuan untuk mempertahankan panjang gelombang pada daerah visible (tampak) (Ramadhani, et al., 2019). Perlakuan inkubasi selama 1 jam sebelum pengukuran dimaksudkan agar reaksi berjalan sempurna, sehingga intensitas warna yang dihasilkan lebih maksimal (Trinovita, et al., 2019). Berdasarkan dari 
hasil penelitian ini diperoleh kadar flavonoid total ekstrak etanol daun kayu manis adalah sebesar 19,554 mg QE/g ekstrak.

\section{SIMPULAN DAN SARAN SIMPULAN}

Ekstrak etanol daun kayu manis (Cinnamomum burmannii Blume) positif mengandung flavonoid dan kadar flovonoid total dari ekstrak etanol daun kayu manis (Cinnamomum burmannii Blume) dengan metode spektrofotometri UV-Vis adalah 19,554mgQE/gekstrak.

\section{SARAN}

Perlu dilakukan penelitian dengan pengekstrak air dan metanol agar dapat dibandingkan kemampuan dari ketiga pelarut polar tersebut mengekstrak kandungan metabolit sekunder golongan flavonoid pada daun kayu manis.

\section{UCAPAN TERIMAKASIH}

Peneliti mengucapkan terimakasih kepada Rektor Universitas Udayana atas biaya penelitian yang disetujui dengan skim DIPA PNBP Universitas Udayana Tahun Anggaran 2021.

\section{DAFTARPUSTAKA}

Anggriawan, M.B., Roswiem, A.P., dan Nurcholis, W., 2015, Potensi Ekstrak Air dan Etanol Kulit Batang Kayu Manis Padang (Cinnamomum Burmanii) Terhadap Aktivitas Enzim A-Glukosidase, Jurnal Kedokteran Yarsi, 23 (2) : 91-102;

Arifin, B. dan Ibrahim, S. 2018. Struktur, Bioaktivitas dan Antioksidan
Flavonoid. Jurnal Zarah. 6 (1) :2129;

Emilda, 2018, Efek Senyawa Bioaktif Kayu Manis Cinnamomum burmanii NEES EX.BL.) Terhadap Diabetes Melitus: Kajian Pustaka, Jurnal Fitofar maka Indonesia, 5 (1) : 246-252;

Ferry, Y. 2013. Prospek Pengembangan Kayu Manis (Cinnamomum Burmanii L) di Indonesia.SIRINOV. 1(1):11-20;

Ramadhani, N., Samudra, A.G.,dan Pratiwi, L.W.I.,2019, Analisis Penetapan Kadar Flavonoid Sari Jeruk Kalamansi (Citrofortunellamicrocarpa) Dengan Metode Spektrofotometri UV-VIS, Jurnal Mandala Pharmacon Indonesia, 6(1) : 53-58;

Saifudin, A., 2002, Senyawa Alam Metabolit :Teori, Konsep, dan Teknik Pemurnian, Deepublish, Solo

Suharyanto,S. dan Hayati, T.N., 2021, Penetapan Kadar Flavonoid Total Ekstrak Buah Gambas (Luffa acutangular (L.) Roxb.) dengan Metode Spektrofotometri UV-Vis, Pharmacon: Jurnal Farmasi Indonesia, 18 (1) : 82-88;

Supriningrum, R., Nurhasnawati, H., dan Putri, M., 2017, Penetapan Kadar Flavonoid EkstrakEtanol Umbi Bawang Tiwai (Eleutherine palmifolia (L.) Merr) Berdasarkan Ukuran Serbuk Simplisia, Media Sains, 10 (1) : 42-46;

Trinovita, Y., Mundriyastutik, Y., Fanani, Z., dan Fitriyani, A.N., 2019, Evaluasi Kadar Flavonoid Total Pada Ekstrak Etanol Daun Sangketan (Achyranthes aspera) Dengan Spektrofotometri, Indonesia Jurnal Farmasi, 4 (1) : 12-18. 